\title{
Artificial surfing reefs in the Mediterranean Sea: an integrated solution for the erosion of the shoreline in Bahía Norte, Alicante
}

\author{
H. Tinoco ${ }^{1}$, L. Aragonés ${ }^{1}$, J. F. Serra ${ }^{2} \&$ Y. Villacampa ${ }^{3}$ \\ ${ }^{1}$ Deptartment of Civil Engineering, University of Alicante, Spain \\ ${ }^{2}$ Department of Transportation, Polytechnic University of Valencia, Spain \\ ${ }^{3}$ Department of Applied Mathematics, University of Alicante, Spain
}

\begin{abstract}
Bahía Norte, located in Alicante, is an artificial coastal area that suffers from erosion, which disturbs the environment, the life and the economy of surrounding areas. In order to mitigate the erosion problem, a solution that provides coastal improvements and allows users to enjoy the structure is proposed. This solution develops artificial surfing reefs as a part of coastal protection management. An artificial surfing reef is not a new concept. However, it is an unknown and innovative idea in the Mediterranean Sea. Given that artificial surfing reefs are a reliable solution for the erosion suffered by the Mediterranean coastline. The project has five aims: controlling the sand loss, providing a recreational area for surfing, improving the security of the swimmers, revitalizing a depressed area and avoiding the visual noise of common structures of coastal defense. Artificial surfing reefs shape new driven current cells that cause an accretion in the shoreline by changing the pre-existing sea currents. Moreover, in order to improve surfing conditions, they fit the shape and height of the incoming waves. This research achieves an alteration of 420 meters of shore with a maximum salient formation of 50 meters, which fits perfectly to the situation of the artificial beach closed by groins. This research has also proved the importance of developing a careful study for the emplacement for this kind of reef being the distance from the structure to the shoreline one of the most determinant factors. It suggests that placing the artificial reef at 200 meters from the coast would be an adequate option.
\end{abstract}

Keywords: artificial surfing reef, ASR, Mediterranean Sea, accretion, currents, surf, submerged reef, Alicante, Bahía Norte. 


\section{Introduction}

The construction of an artificial surfing reef (ASR) consists on the alteration of the seabed shape in order to reshape the existing currents and create new surfing waves. The concept was first described in 1972 by Walker et al. [1].

From then on, 8 ARS have been built in different locations and with different grades of success, and 7 more have been designed around. All of them have been placed in sea areas with similar waves than the Mediterranean ones, with small heights and small periods.

The location of an ASR in the new development of Alicante's shoreline regarding to the project Bahía Norte would not only enhance the situation of a depressed area but it would also provide a recreational body in order to supply the necessities of the local surfer community. The structure leads the reduction of rip currents and the control of the exact point where they take place.

Breakwaters and groins are a common solution for the shoreline defense. However, they cause a negative esthetical impact in the shore landscape (fig. 1A). With an ARS the visual noise is reduced and it provides a base for the growing of sea flora too.

Furthermore, one of the biggest difficulties of the Spanish shoreline is related with its seasonal demand, which is focused on summer. With the construction of an ASR an attractive non-seasonal area would be developed fixing such a problem setting a whole year use.

To sum up, an ASR would achieve the points that follow:

- Coastal defence.

- Economic improvement of a depressed area.

- Ludic area for surfing activities.

- Environmental improvement through the reduction of the visual distortions of common actuations in the shore.
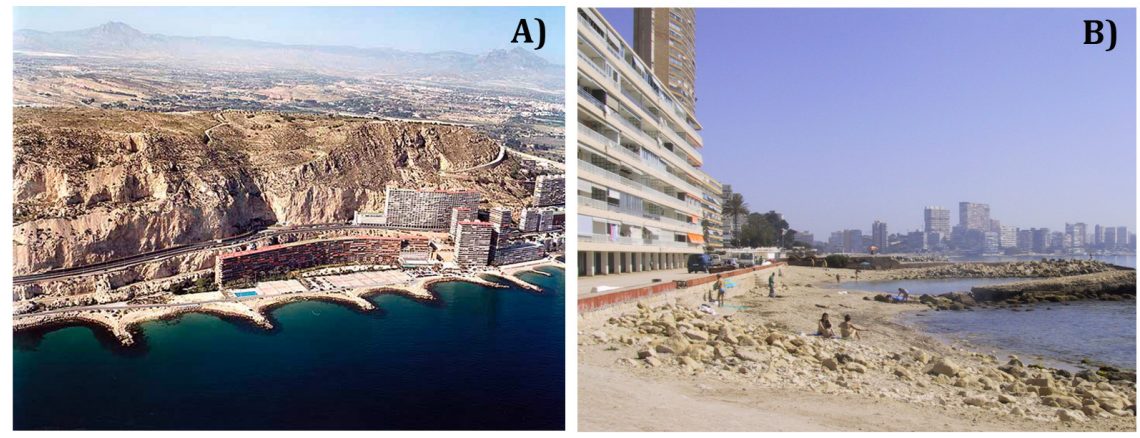

Figure 1: A) Aerial picture of the shore defence development of Bahía Norte.

B) Pressure of the shore by the uncontrolled urbanization plan of Bahía Norte. Source: MAGRAMA. 


\section{Current situation}

Bahía Norte is a depressed area at the shoreline of Alicante due to accumulative facts in time. On the one hand, Bahía Norte became urbanized in a very fast and unregulated way before the Act of 1988 of Coasts. On the other hand, the Act of 1988 set Bahía Norte as a protected public domain, which means that any intervention whatsoever was to be prohibited. Therefore, a badly planned development until 1988 altogether with the impossibility to apply a solution from 1988 on have driven this littoral area to suffer from wave caused erosion for many years. Figure 1B shows the pressure caused by the urban development on the artificial shoreline at Bahía Norte.

Nevertheless, the recently established Act of 2013 allows acting in coastal protected areas to revitalize them. In order to reform the entire seaside of the area, the University of Alicante is developing a full plan that includes the construction of an ASR.

The present article is focused on the artificial beach planned to be created with the artificial sand provided by the quarries of nearby areas. An ASR would be developed onto the designed project in order to promote sport activities next to the rest of mentioned advantages. If the proposed solution was established a clear vision of the seaside from the artificial beach without the common distortions of the breakwaters and groins would be achieved.

\section{Development of the ASR shape}

The present research proposes a "V" shape submerged reef. It comes from the study of the existing ASRs that are summarized in table 1 and so from the study of the team de Aguilar, de Oliveira Filho et al. [2] who proposed that the "V" shape gives more stability to the break than the "Delta" one making it possible to save $\mathrm{m}^{3}$ of the structure as well. The "V" shape of the reef is shown in figure 2.

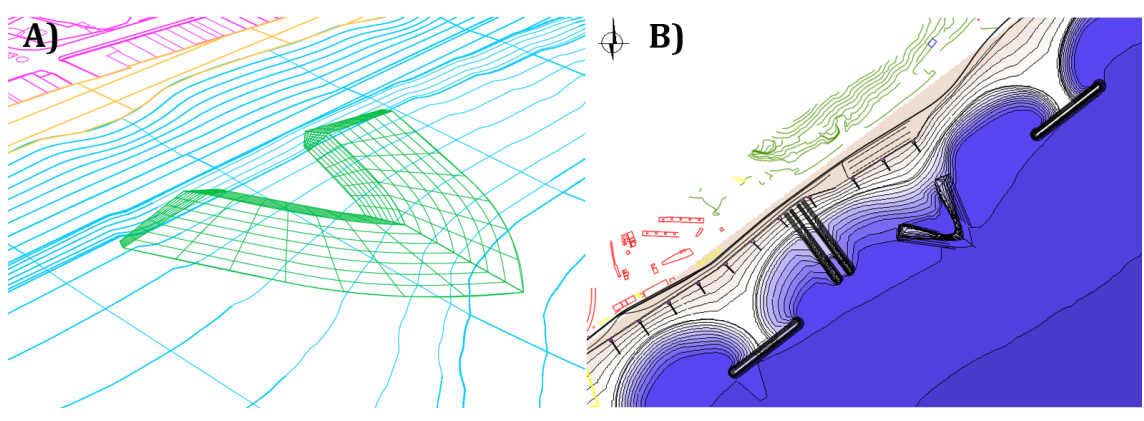

Figure 2: A) 3D modeling of "V" shape. B) Position of ASR2.

The sharpness of the top edge of the reefs is proposed since it would achieve a better focusing of the wave energy and a better control of the wave breaking according to the studies of Henriquez [3]. 
For the design of the ASR shape the formulation of West [4] has been taken into account in order to maximize the amplification of the braking wave factor.

The angle between the vector which describes the wave attack and the orthogonal vector from the arm of the reef is proposed to be one of $66^{\circ}$ so that a progressive brake of the wave would be achieved and so would the best waves to intermediate level surfers do. This angle has been selected according to previous studies of Ten Voorde et al. [5] and Henriquez [3].

\section{Methodology}

In order to predict the effect of the distance to the shoreline of the shaped currents after the construction of the ASR, 6 alternatives have been studied:

1. Without ASR.

2. ASR1: ASR located at 170 meters of distance from the shoreline.

3. ASR2: ASR located at 200 meters of distance from the shoreline.

4. ASR3: ASR located at 300 meters of distance from the shoreline.

5. ASR4: ASR located at 200 meters of distance from the shoreline and relocation of the Northeast groin.

6. ASR5: ASR located at 400 meters of distance from the shoreline.

Shaped currents have been calculated through the SMC. SMC is an application developed by the University of Cantabria and the Hydraulic and Environmental Institute of Cantabria. It provides the necessary tools to calculate and design different actions in the shoreline. For the study of the effect of the shaped currents it has been mainly used the MOPLA modulus, which shows the currents produced by a change in the geomorphology of the seabed.

To study the extreme storms, which the considered area is characterized of, three different systems of available data have been compared, all from the state register network of buoys manage by Puertos del Estado.

Table 1: Existing ASR.

\begin{tabular}{|l|c|c|}
\hline ASR & Date of Construction & Country \\
\hline Bargara & 1997 & Australia \\
\hline Cables & $1998-1999$ & Australia \\
\hline Narrowneck & $1999-2000$ & Australia \\
\hline Prattes & $1999-2001$ & USA \\
\hline Mount Maunganui & $2005-2006$ & New Zealand \\
\hline Opunake & $2006-?$ & New Zealand \\
\hline Boscombe & $2008-2009$ & UK \\
\hline Kovalam & $2009-2010$ & India \\
\hline
\end{tabular}

The study includes a data characterization by REDCOS net (real), SIMAR net (simulated) and WANA net (simulated). It accounts with a comparison of the significant extreme wave heights that attack the studied place. The resume of data is represented in table 2 where $\mathrm{H}_{\mathrm{S}, 0}$ is the significant wave height and $\mathrm{T}_{\mathrm{P}}$ is the peak period associated. 
Since it has given the highest values, the data used to study the stability of the ASR is the one obtained from the REDCOS net.

Table 3 has been developed for the medium regime study of climate. It is used to calculate the magnitude of the strongest driven currents that may take place yearly in the ASR. $\mathrm{H}_{\mathrm{S}, 12} \mathrm{~S}$ is the wave height, exceeded only 12 hours per year, and the $\mathrm{T}_{\mathrm{P}, 12}$ is the peak period associated.

Table 2: Comparative table of extremal wave heights.

\begin{tabular}{|l|l|l|l|l|l|l|}
\cline { 2 - 7 } \multicolumn{1}{c|}{} & \multicolumn{2}{l|}{ REDCOS } & \multicolumn{2}{l|}{ SIMAR } & \multicolumn{2}{l|}{ WANA } \\
\hline Direction & $\mathrm{H}_{\mathrm{S}, 0}$ & $\mathrm{~T}_{\mathrm{P}}$ & $\mathrm{H}_{\mathrm{S}, 0}$ & $\mathrm{~T}_{\mathrm{P}}$ & $\mathrm{H}_{\mathrm{S}, 0}$ & $\mathrm{~T}_{\mathrm{P}}$ \\
\hline NE & - & - & 4,58 & 15,24 & 5,19 & 17,29 \\
\hline ENE & 5,93 & 11,24 & 4,76 & 14,30 & 5,24 & 14,31 \\
\hline E & 5,39 & 10,77 & 4,68 & 14,02 & 4,81 & 14,11 \\
\hline ESE & 4,74 & 10,15 & 2,34 & 12,17 & 2,99 & 14,32 \\
\hline SE & 4,19 & 9,59 & 1,56 & 12,63 & 2,52 & 13,46 \\
\hline SSE & 3,71 & 9,07 & 1,43 & 13,21 & 2,78 & 14,52 \\
\hline S & 3,71 & 9,07 & 2,70 & 12,46 & 3,53 & 13,97 \\
\hline SSW & - & - & 2,74 & 12,45 & 4,61 & 15,74 \\
\hline
\end{tabular}

Table 3: Comparative table of medium wave heights.

\begin{tabular}{|l|l|l|l|l|l|l|}
\cline { 2 - 7 } \multicolumn{1}{c|}{} & \multicolumn{2}{l|}{ BOYA ALICANTE } & \multicolumn{2}{l|}{ SIMAR } & \multicolumn{2}{l|}{ WANA } \\
\hline Direction & $\mathrm{H}_{\mathrm{S}, 12}$ & $\mathrm{~T}_{\mathrm{P}, 12}$ & $\mathrm{H}_{\mathrm{S}, 12}$ & $\mathrm{~T}_{\mathrm{P}, 12}$ & $\mathrm{H}_{\mathrm{S}, 12}$ & $\mathrm{~T}_{\mathrm{P}, 12}$ \\
\hline NE & - & - & 5,17 & 14,9 & 3,70 & 13,5 \\
\hline ENE & 3,08 & 8,32 & 4,10 & 12,3 & 3,50 & 12,3 \\
\hline E & 2,77 & 7,93 & 3,30 & 10,1 & 3,33 & 11,2 \\
\hline ESE & 2,47 & 7,51 & 1,50 & 9,2 & 2,00 & 11,1 \\
\hline SE & 2,16 & 7,06 & 1,10 & 10,1 & 1,90 & 11,2 \\
\hline SSE & 1,87 & 6,61 & 1,00 & 10,1 & 2,23 & 11,2 \\
\hline S & 1,87 & 6,61 & 1,80 & 9,2 & 2,33 & 11,0 \\
\hline SSW & - & - & 1,94 & 11,2 & 3,20 & 12,3 \\
\hline
\end{tabular}

\section{Results}

Figure 3 collects the results of the driven currents produced by the 6 alternatives when a 2 meters wave height and 8 second period storm is simulated. That is the worst situation possibly displayed according to Ranasinghe et al. [6]. It may occur when the storm comes perpendicularly to the shoreline. 


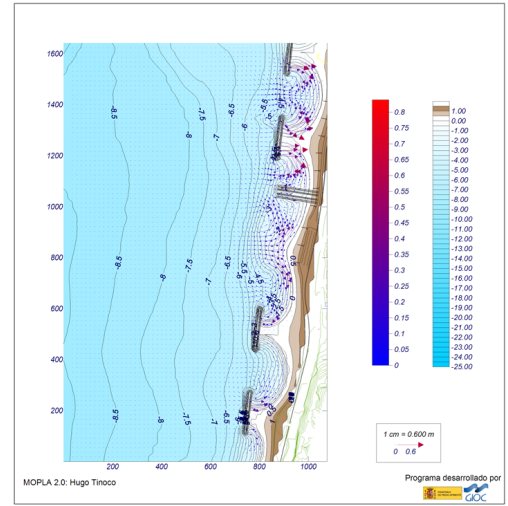

1. Without ASR

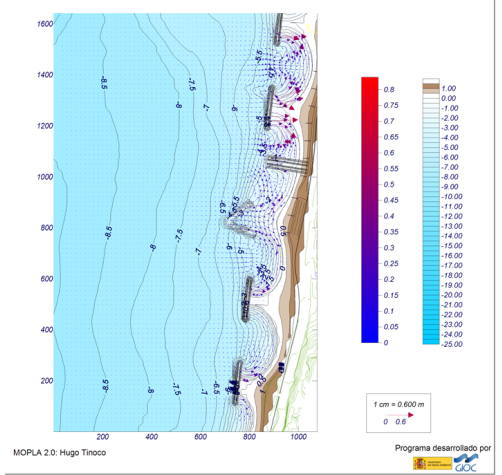

3. ASR2

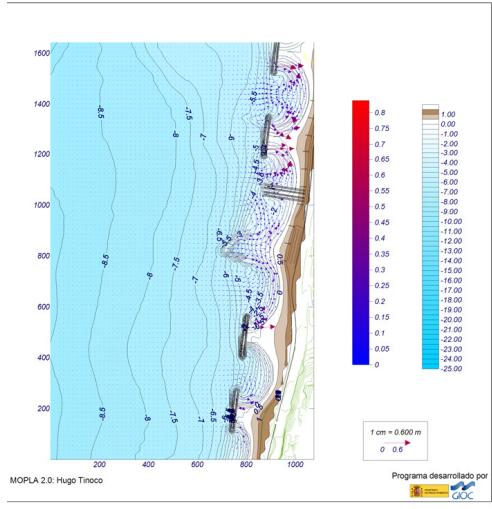

5. ASR4

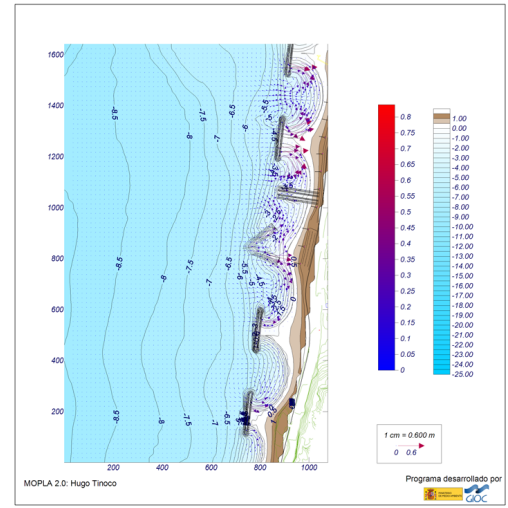

2. ASR1

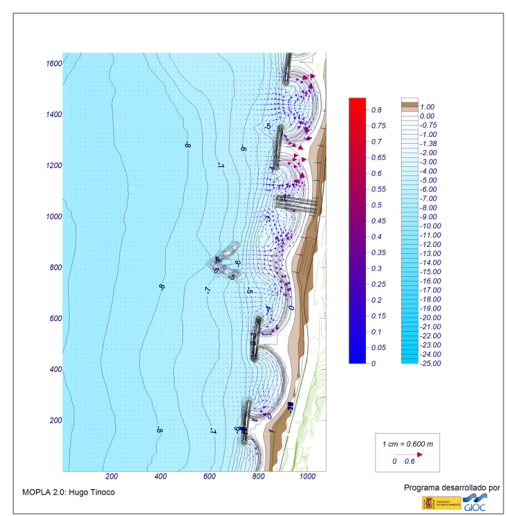

4. ASR3

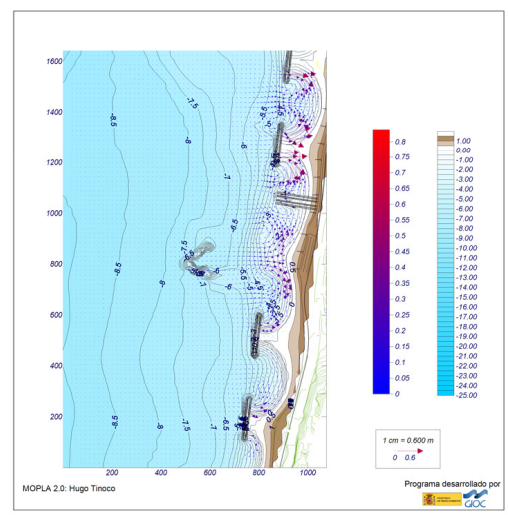

6. ASR5

Figure 3: Studied alternatives with the shaped currents in each case for a perpendicular wave attack. 
The ARS has been located in five different positions observing how the currents over the shoreline are affected. Firstly, without the ARS, the magnitude of the existing currents has been studied. In second place, ASR1, after placing the submerged reef near the shore the currents have become stronger than in the first step. In the third step, ASR2, after placing the submerged reef in an intermediate distance the currents have become less strong than in the case without ARS. Moreover, three more dispositions have been developed in order to prove the importance of the distance between the shoreline and the ASR according to the magnitude and shape of the generated currents.

In order to calculate the distance which the ARS has to be placed at equation 1 of Ranasinghe et al. [6] has been used.

$$
\frac{h_{b}}{H_{0}}=2 \log _{10}\left\{\left(\frac{s_{B}}{h_{b}}\right)^{3 / 2}\left(\frac{L_{B}}{h_{b}}\right)^{2}\left(\frac{A^{3}}{h_{b}}\right)^{1 / 2}\right\}+0.65
$$

where:

$h_{b} \rightarrow$ Depth of the seabed in the emplacement of the ASR.

$H_{0} \rightarrow$ Significant wave height in deep water.

$s_{B} \rightarrow$ Depth of the top of the ASR.

$L_{B} \rightarrow$ Length of the submerged structure.

$A \rightarrow$ Scale parameter of Dean.

$$
A=0.21 \cdot D_{50}{ }^{0,48}
$$

The ARS has been estimated to be located 170 meters in offshore direction and therefore the breaking zone would be located at a distance of 170 meters from de coast as well.

Considering:

$\mathrm{h}_{\mathrm{B}}=3.52 \mathrm{~m}$

$x_{B} \rightarrow 170 \mathrm{~m}$.

$H_{0} \Rightarrow \mathrm{H}_{\mathrm{S} 12}=2.47 \mathrm{~m}$.

$s_{B} \rightarrow 0.7 \mathrm{~m}$.

$A=0.21 \cdot 1.746^{0.48} \rightarrow A=0.274$

Operating with the equation 1 of Ranasinghe et al. [6] and equation 2 of Dean [7] in order to calculate the scale parameter and taking in account that $\left(\frac{s_{B}}{h_{B}}\right)^{3 / 2}\left(\frac{L_{B}}{h_{B}}\right)^{2}\left(\frac{A^{3}}{h_{B}}\right)^{1 / 2}$ has to be between the values of 0.1 and 2.5 for the relation $\frac{\mathrm{h}_{\mathrm{b}}}{\mathrm{H}_{0}}=1.425$ in order to achieve the accretion in the shoreline. The wide of the submerged structure has to be between 13.46 meters and 67.3 meters. For that reason the selected wide to the ASR has been over 65 meters, which means 
that the distance between the arms of the structure on its top in the middle of the ASR is 65 meters.

However, the formula of Ranasinghe et al. [6] does not fit well enough in this specific case. The reason of the discordance might be due to the proximity of the breakwaters to the reef since a similar ASR in an isolated location has been developed in order to prove that the Ranasinghe et al. [6] formula works in the Mediterranean sea [Tinoco's unpublished works].

Figure 4 shows the accretion and the shape of the four cells of currents described by the mentioned authors.
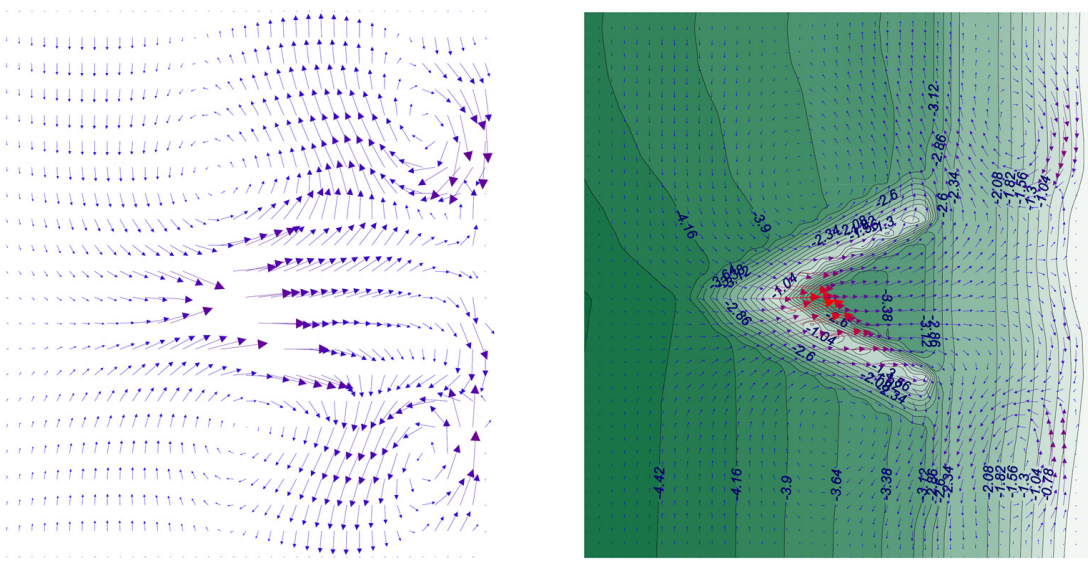

Figure 4: ARS studied in the Mediterranean Sea. Source: Tinoco's unpublished paper.

The research has kept the wide of the reef constant only varying the distance.

Case 4 (ARS3) has shown an intermediate state between the case 1, without ARS, and the third case (ASR2). The location of the ARS is consequently very important regarding to the formation of the currents.

Within the four cases studied, the most favorable one is ARS 2 i.e. the intermediate position of the ASR. Moreover it has been detected that in the ASR5 located at 400 meters the influence over the shore is inappreciable (fig. 5).

A decrease on the strength of currents is observed when the northeast storms waves are studied after placing the ASR2. This decreasing magnitude is shown in figure 6 where the image A represents the case ASR2 and the image B represents the case without ASR. Reduction of such currents is observed in the sheltered area provided by the reef due to the smaller quantity and size of vectors.

The most effective emplacement of the structure is related with the alternative 3 , i.e. ASR2. Placing the artificial reef at 200 meters from the coast a reduction of the preexisting currents is achieved. 


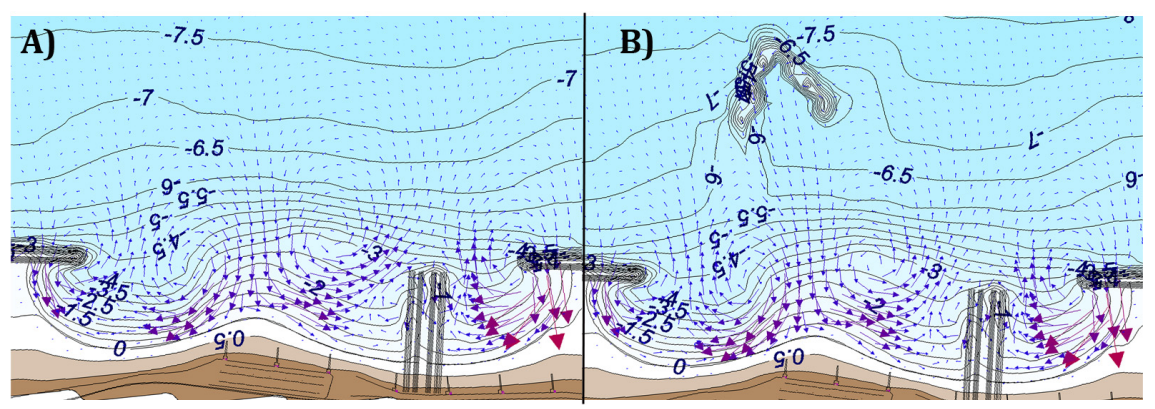

Figure 5: Shaped currents from: A) Alternative 1. B) Alternative 6.

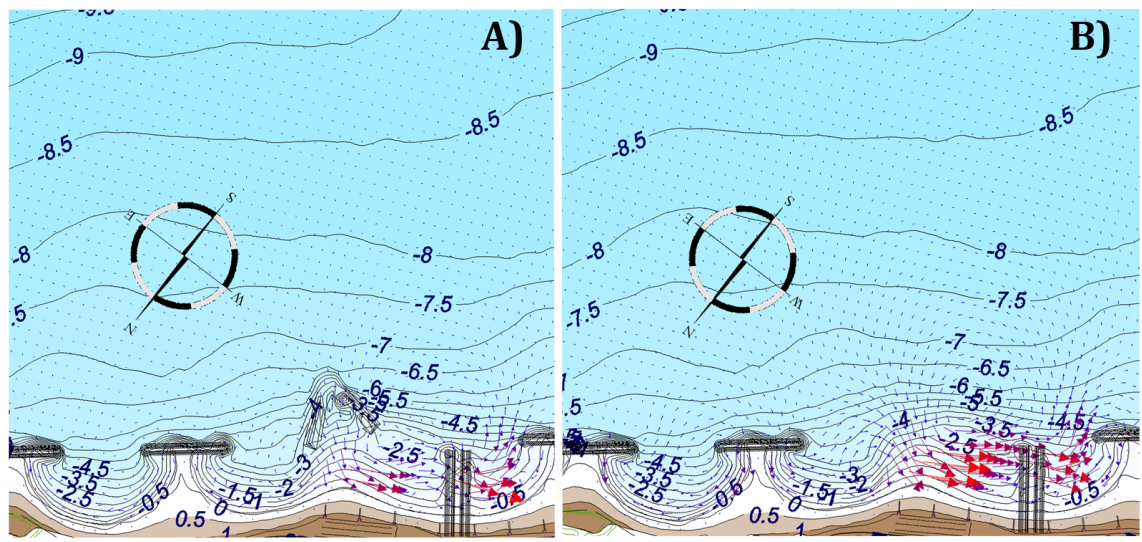

Figure 6: NE incident wave currents. A) Case without ASR. B) ASR2.

Figure 7 shows how the control of the currents that cause the loss of the sand in the case without ASR is achieved. Two groins are placed in the area with the mission of controlling the erosion during rainfall periods. These two groins are the ending of a canalization that collects the rainwater and drives it to the sea in order to avoid floods in nearby areas. One of these groins is the support of the southern part of the designed artificial beach. The study of currents in this area has shown a trend to loss the sand out of the beach due to the shaped driven currents. This loss of sand is controlled in alternative 3, ASR2. Both cases are represented in the figure 7 showing the obtained improvement after placing the submerged reef.

Furthermore with the construction of this type of coastal defense element it becomes possible to focus the rip currents in a specific place contributing to swimmers' safety. The dangerous emplacements could be signalized. They are prone to be dangerous due to the strongest currents produced in them. Lifeguards would focus on them taking care of unconscious swimmers in these locations. 


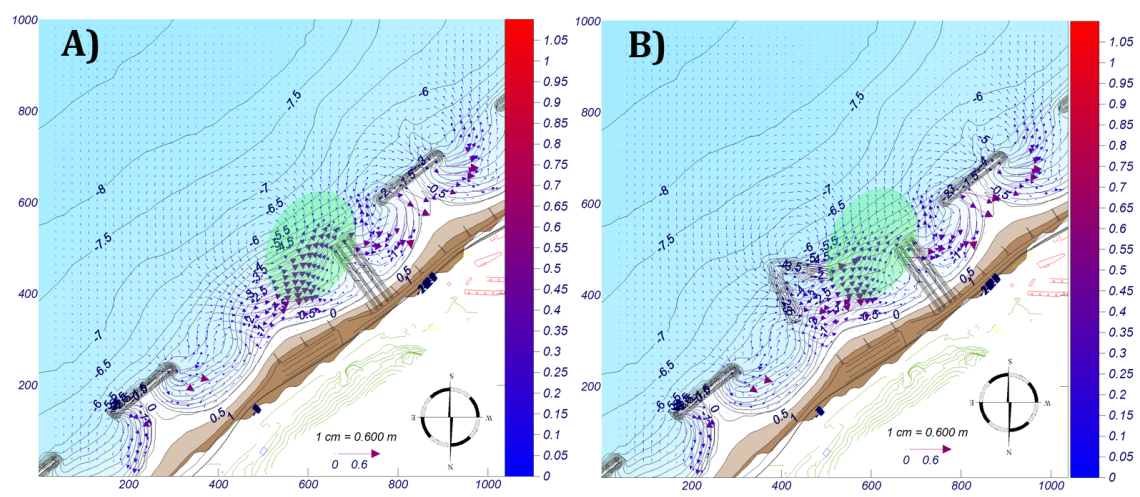

Figure 7: Control of the sand loss after placing the ASR2. A) Case without ASR. B) Alternative 3 or ASR2.

\subsection{Salient formation}

In order to make an approximate calculus of the accretion caused after placing the ASR2 it has been used the specific formulae from Black and Andrews [8] and Black and Andrews [9].

The research carried out by these authors presents the ratio between the maximum wide of the reef $(B)$ and its distance to the shore $(S)$ as a major parameter in order to calculate the salient formation.

In figure 8 it is shown the value of these parameters. Being $S$ equal to 106.9 meters and $B$ equal to 99.6 meters. In order to calculate the salient formation it has been applied de equation 3 .

$$
\frac{X_{\text {off }}}{B}=0.50 \cdot\left(\frac{B}{S}\right)^{-1,27} \rightarrow \text { For reefs }\left(r^{2}=0.96\right)
$$

Obtaining the equation 4 which represents the salient formation generated by the ASR2. This salient formation is represented in the figure 10, and affects a total of 420 meters shaping a maximum accretion of 50 meters as it is shown in the table 4 and in figure 8.

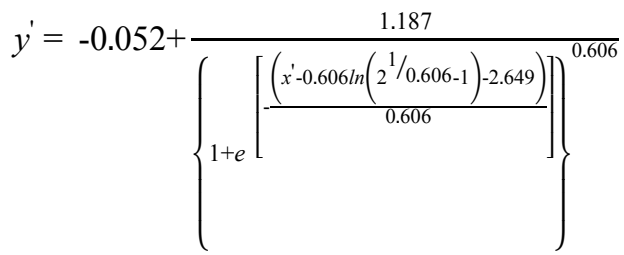




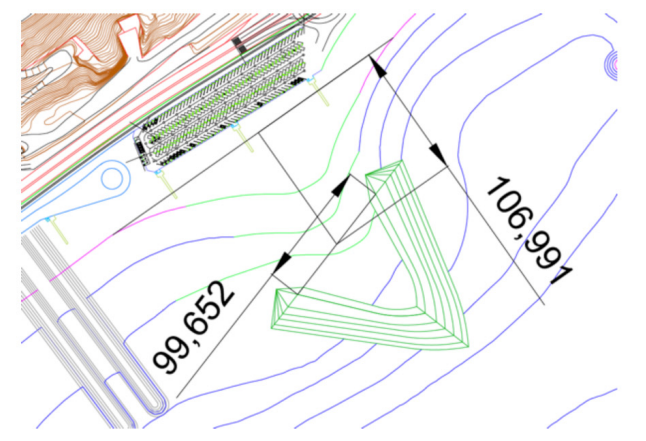

Figure 8: Salient formation of ASR2.

Table 4: Datasheet of salient formation.

\begin{tabular}{|c|c|c|c|}
\hline $\mathbf{x}^{\prime}$ & $\mathbf{y}^{\prime}$ & $\mathbf{X}$ & $\mathbf{Y}$ \\
\hline 0 & 0.00 & 0.0 & 0.0 \\
\hline 0.2 & 0.01 & 10.5 & 0.6 \\
\hline 0.4 & 0.03 & 21.0 & 1.4 \\
\hline 0.6 & 0.04 & 31.5 & 2.3 \\
\hline 0.8 & 0.06 & 42.0 & 3.4 \\
\hline 1 & 0.09 & 52.5 & 4.7 \\
\hline 1.2 & 0.12 & 63.0 & 6.3 \\
\hline 1.4 & 0.16 & 73.5 & 8.2 \\
\hline 1.6 & 0.20 & 84.0 & 10.4 \\
\hline 1.8 & 0.25 & 94.5 & 13.0 \\
\hline 2 & 0.31 & 105.0 & 16.0 \\
\hline 2.2 & 0.37 & 115.5 & 19.5 \\
\hline 2.4 & 0.44 & 126.0 & 23.3 \\
\hline 2.6 & 0.52 & 136.5 & 27.4 \\
\hline 2.8 & 0.60 & 147.0 & 31.7 \\
\hline 3 & 0.68 & 157.5 & 35.9 \\
\hline 3.2 & 0.76 & 168.0 & 40.0 \\
\hline 3.4 & 0.83 & 178.5 & 43.8 \\
\hline 3.6 & 0.90 & 189.0 & 47.1 \\
\hline 3.8 & 0.95 & 199.5 & 49.9 \\
\hline 4 & 0.99 & 210.0 & 52.2 \\
\hline
\end{tabular}

\begin{tabular}{|c|c|c|c|}
\hline $\mathbf{x}^{\prime}$ & $\mathbf{y}^{\prime}$ & $\mathbf{X}$ & $\mathbf{Y}$ \\
\hline 4 & 0.99 & 210.0 & 52.2 \\
\hline 4.2 & 0.95 & 220.5 & 49.9 \\
\hline 4.4 & 0.90 & 231.0 & 47.1 \\
\hline 4.6 & 0.83 & 241.5 & 43.8 \\
\hline 4.8 & 0.76 & 252.0 & 40.0 \\
\hline 5 & 0.68 & 262.5 & 35.9 \\
\hline 5.2 & 0.60 & 273.0 & 31.7 \\
\hline 5.4 & 0.52 & 283.5 & 27.4 \\
\hline 5.6 & 0.44 & 294.0 & 23.3 \\
\hline 5.8 & 0.37 & 304.5 & 19.5 \\
\hline 6 & 0.31 & 315.0 & 16.0 \\
\hline 6.2 & 0.25 & 325.5 & 13.0 \\
\hline 6.4 & 0.20 & 336.0 & 10.4 \\
\hline 6.6 & 0.16 & 346.5 & 8.2 \\
\hline 6.8 & 0.12 & 357.0 & 6.3 \\
\hline 7 & 0.09 & 367.5 & 4.7 \\
\hline 7.2 & 0.06 & 378.0 & 3.4 \\
\hline 7.4 & 0.04 & 388.5 & 2.3 \\
\hline 7.6 & 0.03 & 399.0 & 1.4 \\
\hline 7.8 & 0.01 & 409.5 & 0.6 \\
\hline 8 & 0.00 & 420.0 & 0.0 \\
\hline
\end{tabular}




\section{Conclusion}

A "V" shape ASR has been developed inside the reconstruction of the shore of the Bahía Norte in Alicante. Spain. Five goals would be achieved through this project: controlling the sand loss, providing a recreational area, improving the security of the swimmers, revitalizing a depressed area and avoiding the visual noise of common structures of coastal defense.

The Spanish Mediterranean shore suffers from erosion. It is losing about one meter of dry beach per year in certain areas.

The development of such costal defense and ludic structures would bring a solution to the erosion problem in some specific points of the shore.

This research has proved the importance of developing a careful study for the emplacement for this kind of reef being the distance from the structure to the shoreline one of the most determinant factors.

It suggests that alternative 3 or ASR2 is the best option, placing the artificial reef at 200 meters from the coast.

ASRs shape new driven current cells that cause an accretion in the shoreline by changing the pre-existing sea currents. Moreover, in order to improve surfing conditions, they fit the shape and height of the incoming waves. It has been achieved an alteration of 420 meters of shore with a maximum salient formation of 50 meters which fits perfectly to the situation of the artificial beach closed by groins.

To conclude. ASRs are sustainable projects. They are a reliable solution for the erosion suffered by the Mediterranean coastline, which also integrates people with costal structures improving the shoreline development.

\section{References}

[1] Walker J.R.. Palmer R.Q. \& Kukea J.K. Recreational Surfing On Hawaii Reefs. Coastal Engineering. (Hawaiian Reefs Chapter 151) pp. 2609-2628. 1972.

[2] de Oliveira Filho L., de Aguilar L. \& Valentini E. Proposed Artificial Surfing Reef for Macumba Beach. Rio de Janeiro-Brazil. Reef Journal. (1) pp. 74-84. 2009.

[3] Henriquez M. Artificial Surf Reefs. Delf University of Technology. PhD Thesis. 2004.

[4] West A. Wave-focusing Surfing Reefs a New Concept. Delf University of Technology. PhD Thesis. 2002.

[5] Ten Voorde M.. Do Carmo J. \& Neves M. Artificial Surfing Reefs: The Preparation of Physical Test and the Theory Behind. Proc. of the $1^{\text {st }}$ International Conference on the Application of Physical Modelling to Port and Coastal Protection. 2006.

[6] Ranasinghe R.. Larson M. \& Savioli J. Shoreline response to a single shoreparallel submerged breakwater. Coastal Engineering. (57) pp. 1006-1017. 2010 . 
[7] Dean R.G. Equilibrium Beach Profiles. US Atlantic and Gulf Coasts. Department of Civil Engineering. Newark. Delaware. University of Delaware. 1977.

[8] Black K.P. \& Andrews C.J. Sandy Shoreline Response to Offshore Obstacles. Part 1: Salient and Tombolo Geometry ans Shape. Journal of Coastal Research. (S.I. 29) pp. 82-93. 2001 a.

[9] Black K.P. \& Andrews C.J. Sandy Shoreline Response to Offshore Obstacles Part 2: Discussion of Formative Mechanisms. Journal of Coastal Research. (S.I. 29) pp. 94-101.2001b. 